\title{
Posterior and anterior sulcus tumors
}

\author{
Francesca Signore ${ }^{1 \#}$, Teodora Panza ${ }^{1 \#}$, Debora Brascia $^{1}$, Giulia De Iaco ${ }^{1}$, Angela Fiorella ${ }^{1}$, \\ Marcella Schiavone ${ }^{1}$, Alessandro Geronimo ${ }^{1}$, Doroty Sampietro ${ }^{1}$, Federico Rea ${ }^{2}$, Giuseppe Marulli ${ }^{1}$
}

${ }^{1}$ Thoracic Surgery Unit, Department of Organ Transplantation and Emergency, University Hospital of Bari, Bari, Italy; ${ }^{2}$ Thoracic Surgery, University of Padova, Padova, Italy

Contributions: (I) Conception and design: F Signore, T Panza, G Marulli; (II) Administrative support: All authors; (III) Provision of study materials or patients: All authors; (IV) Collection and assembly of data: All authors; (V) Data analysis and interpretation: F Signore, T Panza, G Marulli; (VI) Manuscript writing: All authors; (VII) Final approval of manuscript: All authors.

\#These authors equally contributed to this work.

Correspondence to: Prof. Giuseppe Marulli. Thoracic Surgery Unit, Department of Organ Transplantation and Emergency, University Hospital of Bari, P.zza Giulio Cesare, 1170124 - Bari, Italy. Email: giuseppe.marulli@uniba.it; beppemarulli@libero.it.

\begin{abstract}
Pancoast or superior sulcus tumors are rare lung lesions arising from the apex of the lung located above the level of the second rib invading vital structures such as first rib, lower roots of the brachial plexus, subclavian vessels, stellate ganglion, sympathetic trunk, and adjacent vertebral bodies. They may be responsible for characteristic symptoms such as pain from the shoulder to anterior chest wall, arm pain and weakness and atrophy of the hand, Claude-Bernard-Horner Syndrome and upper arm oedema. Pancoast tumors are frequently caused by non-small cell lung cancer and for many years they were considered fatal for their malignity and not amenable for surgery until 1950s when Chardack and MacCallum described a successful bimodal treatment including surgical resection followed by postoperative irradiation. In 1966, Paulson proposed a combined preoperative radiation therapy followed by en bloc resection of lung and chest wall through a postero-lateral approach. In the late 1990s, some authors began to study a new trimodality approach based on the combination of chemo-radiotherapy followed by surgery obtaining an improvement of systemic and local control of the disease. However, a remarkable variability still exists between in terms of chemiotherapic medications, number and timing of administration, modality and dose of radiotherapy and eligibility criteria. Different surgical approaches have been described based on location of the tumor and invaded structures: anterior approach for superior sulcus tumors invading subclavian vessels and first rib; posterior approach for the management of tumors invading the posterior thoracic inlet, particularly the vertebrae; combined approaches according to the degree of inlet involvement.
\end{abstract}

Keywords: Superior sulcus tumor; thoracic inlet; non-small cell lung cancer; Pancoast tumor

Received: 15 April 2020; Accepted: 14 May 2020; Published: 25 February 2021.

doi: $10.21037 /$ ccts-20-81

View this article at: http://dx.doi.org/10.21037/ccts-20-81

\section{Introduction}

Pancoast or superior sulcus tumors are rare lung lesions arising from the apex of the lung accounting for less than $5 \%$ of all bronchogenic carcinomas (1). These lesions include benign or malignant tumors located above the level of the second rib invading vital structures such as first rib, lower roots of the brachial plexus, subclavian vessels, stellate ganglion, sympathetic trunk, and adjacent vertebral bodies (2).

From a clinical point of view, some almost pathognomonic indicators should lead to the suspect of a Pancoast tumor: pain from the shoulder to anterior chest wall, neurologic symptoms for the involvement of the ulnar nerve as arm pain and weakness and atrophy of the hand, Claude-Bernard-Horner Syndrome (ptosis, miosis, enophthalmos and anhidrosis of the ipsilateral side of the face) caused by the invasion of the sympathetic chain 
and the stellate ganglion, upper arm oedema in case of infiltration of the subclavian vein (3).

\section{History}

Pancoast tumors are frequently caused by non-small cell lung cancer and for many years they were considered fatal for their malignity and not amenable for surgery.

In 1924, Pancoast (4) defined these lesions for the first time, describing radiographic and clinical findings associated with superior sulcus tumors. In 1932, Pancoast (5) reported four case reports who presented with weakness and wasting of the muscles of hand, pain in the shoulder and arm and ipsilateral Horner's syndrome. Pancoast rejected the pulmonary origin, he initially thought they arose from epithelial rest cells from the fifth brachial cleft. Eight years later, Tobías (6) recognized bronchogenic origin as primary cause of this syndrome and described its anatomical and clinical aspects.

As reported by Walker (7) and Herbut et al. (8), superior sulcus tumors have been considered inoperable and have been treated with palliative radiotherapy until 1950s, when Chardack and MacCallum described a successful treatment based on a bimodal treatment including surgical resection followed by 65 Gy postoperative irradiation (9).

In 1966, Paulson proposed a combined preoperative radiation therapy (30 to $45 \mathrm{~Gy}$ in four weeks) followed by en bloc resection of lung parenchima and chest wall through a postero-lateral approach (10), which had been proved to provide a $10 \%$ to $35 \% 5$-years survival rate (11). For this reason, the bimodal therapy became the standard treatment of Pancoast tumor.

In the late 1990s, some authors (12-15) began to study a new trimodality approach based on the combination of chemo-radiotherapy followed by surgery obtaining an improvement of systemic and local control of the disease thanks to high pathological response and radical resection rates.

\section{Role of multimodality treatment and prognosis}

According to the $8^{\text {th }}$ Edition of the tumor, node and metastasis (TNM) classification of Lung Cancer based on the International Association for the Study of Lung Cancer (IASLC) Staging Project, the Pancoast tumor is classified as T4 in case of involvement of the spine, subclavian vessels and/or the rostral roots of the brachial plexus (C8 or above) otherwise the tumor is classified as T3.
Since the publication of the ACCP Guidelines (16), the management of the Pancoast tumors has been aligned to that of the others IIB, IIIA, IIIB stage non-small cell lung cancer (NSCLC) but with some special considerations because of the unique characteristics of the region where these tumors occur.

The ACCP Guidelines such as the NCCN Guidelines (17) are based on the two most important studies concerning the management of Pancoast tumor: the Southwest Oncology Group prospective multi-institutional phase II trial (SWOG 9416) (18) and the Japan Clinical Oncology group phase II trial (JCO 9806) (19). Both these studies compared trimodality approach based on chemo-radiotherapy and surgical resection to the previous bimodality radio-surgical approach. Five-years survival rates reached $44 \%$ and $56 \%$ in the SWOG 9416 and the JCO 9806 study, respectively. According to these results, the standard treatment has been recognized to be a synergy of induction CHT/RT and radical surgical resection. However, a remarkable variability still exists between Centers in induction protocols, with regard to cytotoxic drugs, number of chemotherapy cycles, mode and intensity of radiotherapy, in terms of chemotherapic medications, number and timing of administration, modality and dose of radiotherapy and eligibility criteria (i.e., inclusion/exclusion from surgery of $\mathrm{N} 2$ /supraclavicular N3 or T4 tumors).

Table 1 resumes results of the main studies published in the last 20 years.

Another challenging point is that nowadays the available imaging technologies can not exactly calculate the pathological response rate after induction therapy, therefore it may be difficult to distinguish between persistent tumor or residual fibrosis only (Figure 1).

Some concerns have also been made about the timing of this multimodality approach. Solli et al. (26), and previously Alifano et al. (36), as Waseda et al. (25) had already considered a strategy based on surgery upfront and adjuvant treatment, in particular in patients with an impaired performance status at presentation, excluding those with N2/3 nodal involvement. Even nowadays the nodal involvement is considered a negative prognostic factor and there is no common stand about N2 disease and role of surgery, yet (26).

It is thought that induction-therapy complications could delay or prevent surgery, that instead could provide to the patient an immediate disease and symptoms control.

For this reason, in each case the feasibility of a complete resection should be previously evaluated in order to 


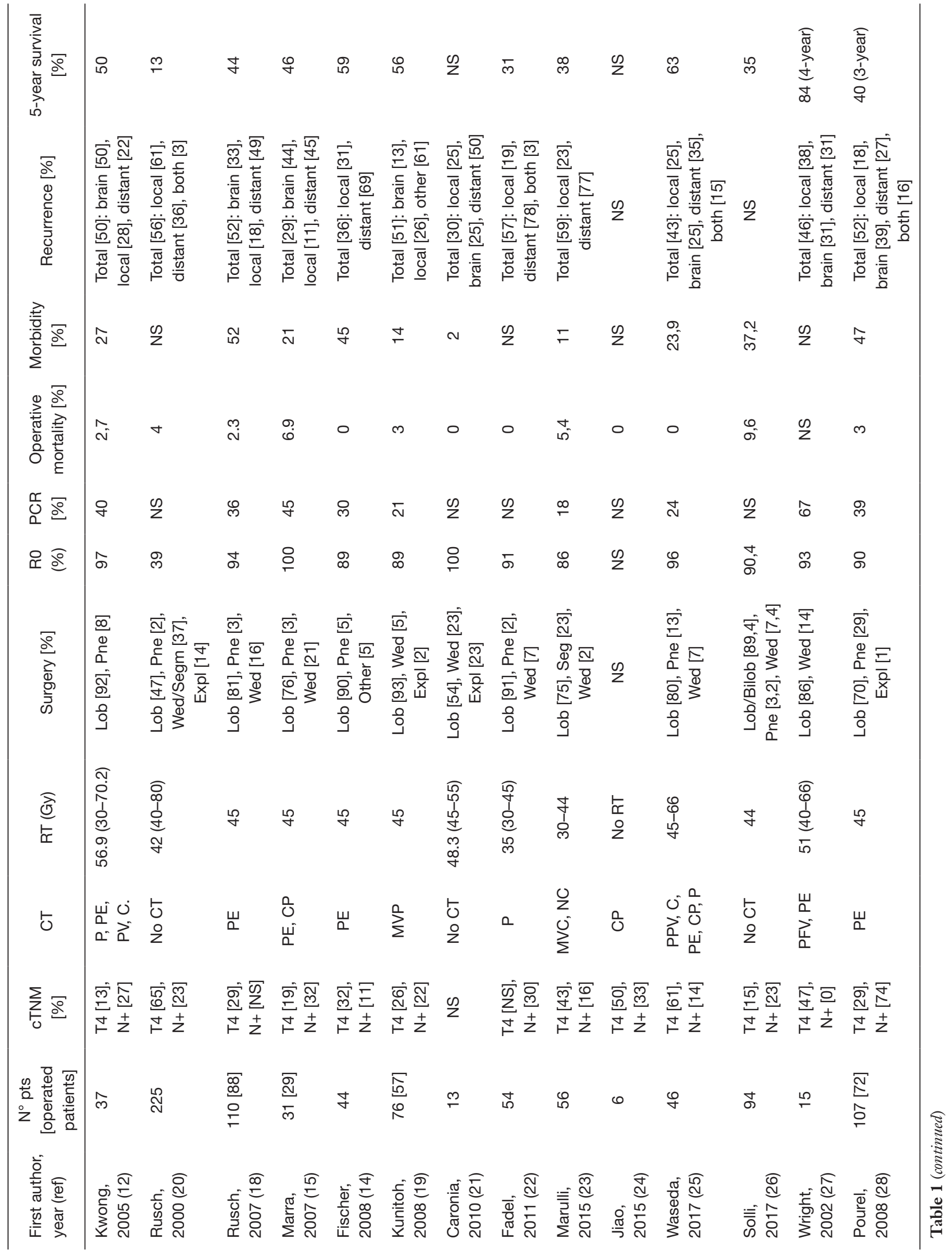




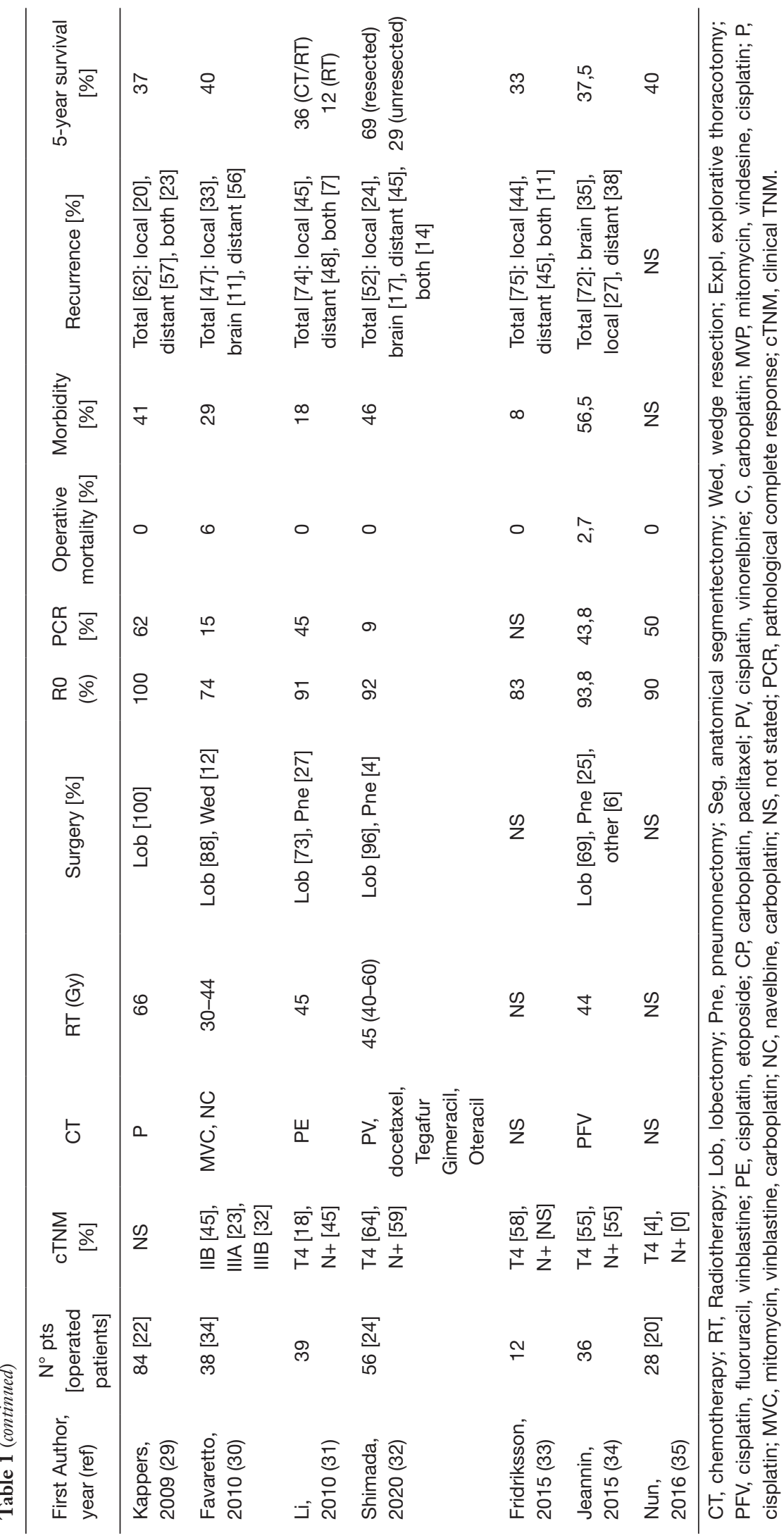



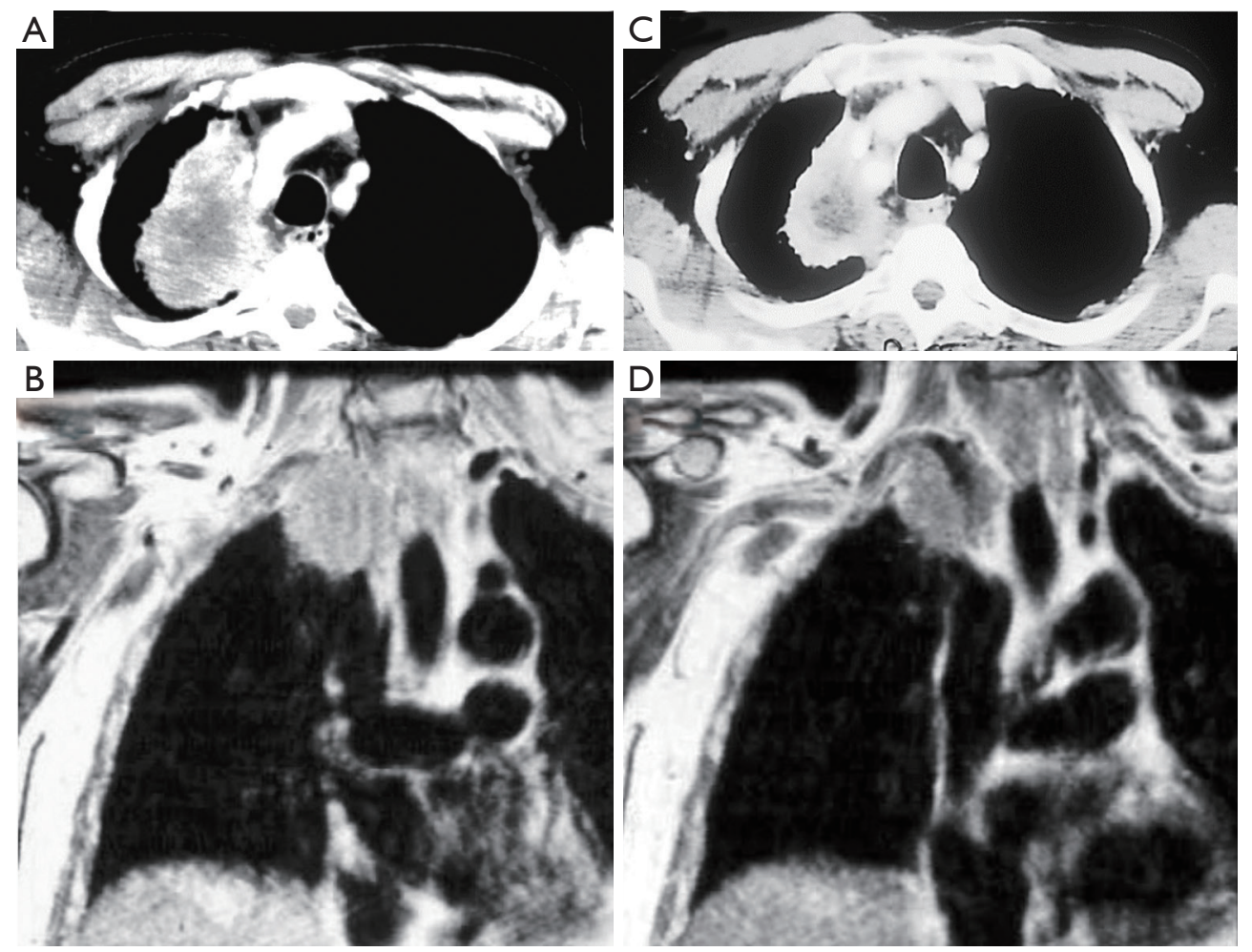

Figure 1 Computer Tomography (CT) Scan and Magnetic Resonance Imaging (MRI) of the same patient before (A,B) and after (C,D) induction therapy: the effect of the chemo-radiotherapy is a significative volume decrease with a necrosis of the central part of the mass.

start with surgical treatment and subsequently to begin the adjuvant treatment. In this way, the post-operative therapy could be better sized on the patient based on the pathological results: chemotherapy in case of unsuspected positive supraclavicular or mediastinal lymph-nodes and radiotherapy or chemo-radiotherapy in case of positive resection margins.

Regarding the prognostic role of $\mathrm{T}$ status, the majority of the available studies found a poor survival rates for T4 tumors due to the low rate of radical resection (20). In a recent study by Waseda et al. (25), however, despite the high percentage of locally advanced tumors and extended procedures, they have reported a 5 -years overall survival of $63 \%$ with no significant detriment for T4 tumors compared to T3. These data suggest that radical resections in $\mathrm{T} 4$ tumors can achieve similar favorable results as for T3 tumors.

\section{Surgery}

Because of the complex anatomy of the thoracic inlet, there has been an evolution of surgical techniques and currently these tumors are classified considering scalene muscles' position on the first rib as anterior, middle and posterior tumors (37) (Figure 2).

Similarly, the surgical approaches have been defined depending on the site of the lesion: anterior approach for superior sulcus tumors invading subclavian vessels and first rib; posterior approach for the management of tumors invading the posterior thoracic inlet, particularly the vertebrae; combined approaches according to the degree of inlet involvement.

The first approach was described by Shaw and Paulson in 1961 (38) and consists of a postero-lateral thoracotomy that has been the standard surgery technique for Pancoast tumor for many years.

The particular aspect of the Shaw-Paulson approach is the extension of the classical postero-lateral thoracotomy posteriorly surrounding the tip of the scapula and vertically up to C7: the latissimus dorsi, the trapezius, the serratus anterior, the rhomboids major and minor and the elevator of the scapula muscles should be dissected, while the serratus posterior superior muscle should be preserved to be used as a flap. To guarantee large free margins, the ribs have to be resected anteriorly $3-4 \mathrm{~cm}$ away from the lesion including 

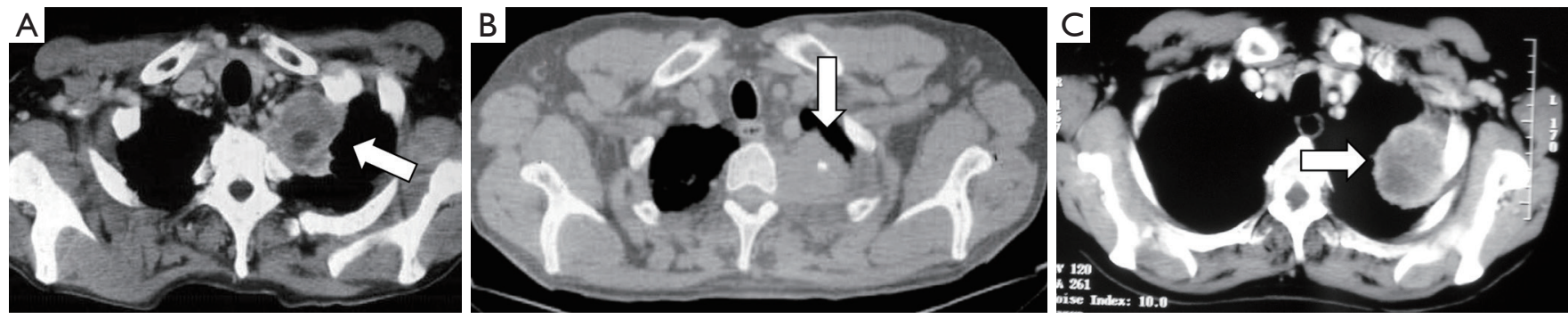

Figure 2 CT scan images showing three typical localizations of Pancoast tumor (white arrows): (A) anterior; (B) posterior; (C) lateral.
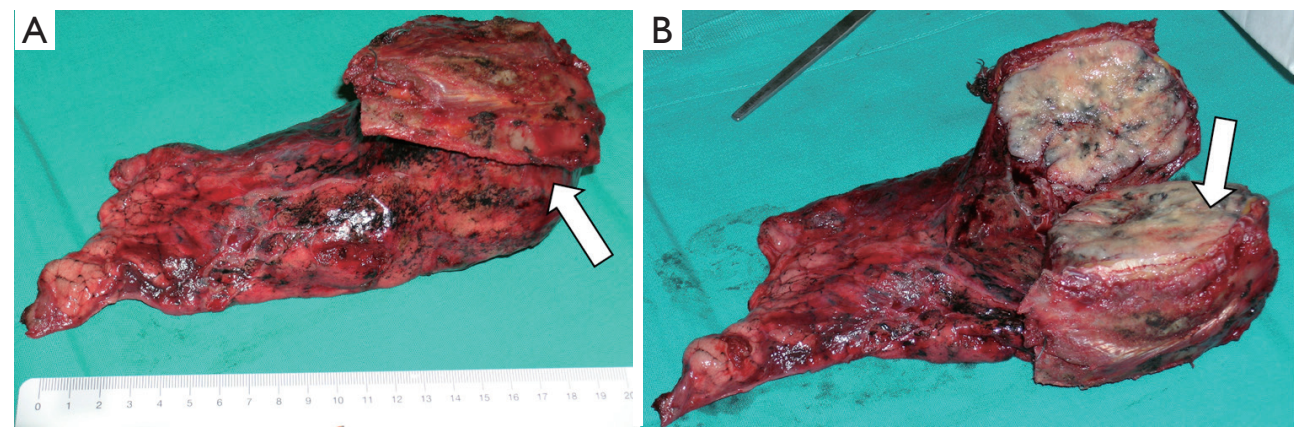

Figure 3 Surgical specimen of en bloc resection of a superior sulcus tumor: the mass is resected together with the thoracic wall (white arrow, A) and the lung (performing a lobectomy, white arrow, B).

an intercostal space below (Figure 3). Posteriorly, once retracted the erector spinae muscle, in case of involvement of the parietal pleura only, the rib can be disarticulated from the transverse process, otherwise the transverse process has to be removed as long as the contiguous lateral cortex of the vertebrae.

Since the begin, this approach showed its limits when managing tumors invading anterior structures such as subclavian vessels and their branches; for this reason, during the years, various anterior approaches have been described.

In the 1990s, Dartevelle and Colleagues described the anterior transcervical approach (39). Patient is placed in a supine position with head turned contralaterally to the involved side. An L-shaped skin incision is made along the anterior border of sternocleidomastoid muscle prolonged horizontally below the clavicle up to the delto-pectoral groove. The sternocleidomastoid muscle is sectioned at its attachment to the clavicle which is medially resected. Subsequently, the anterior scalene muscle is resected (avoiding injury of the phrenic nerve), the scalene fat pad is dissected and examined to exclude scalene lymph nodes metastasis. This approach allows a great exposure of the subclavian vessels and of the brachial plexus and possibility to perform a chest wall resection. Dartevelle suggested a wedge resection on the lung because performing a lobectomy could be very challenging through this approach, necessitating a thoracotomy.

The advantages of the anterior transcervical approach are the excellent exposure of the thoracic inlet with a safe treatment of the subclavian vessels and related branches, phrenic nerve and brachial plexus, providing an uncomplicated visualization of the apex of the lung. Moreover, it offers minimal postoperative discomfort, negligible morbidity and long-term survival.

Disadvantages include longer operative time and aesthetic deformities of the shoulder because of resection of both the clavicle and the external branches of the accessory nerve.

In 1997, Grunenwald and Spaggiari (40) refined the anterior transcervical approach with a transmanubrial L-shaped incision which allows exposure of the anterior portion of the thoracic inlet, sparing osteomuscular components of the cervical and shoulder articulations. The L-shapes cervicotomy incision is made with the upper line on anterior part of sternocleidomastoid as far as the angle 

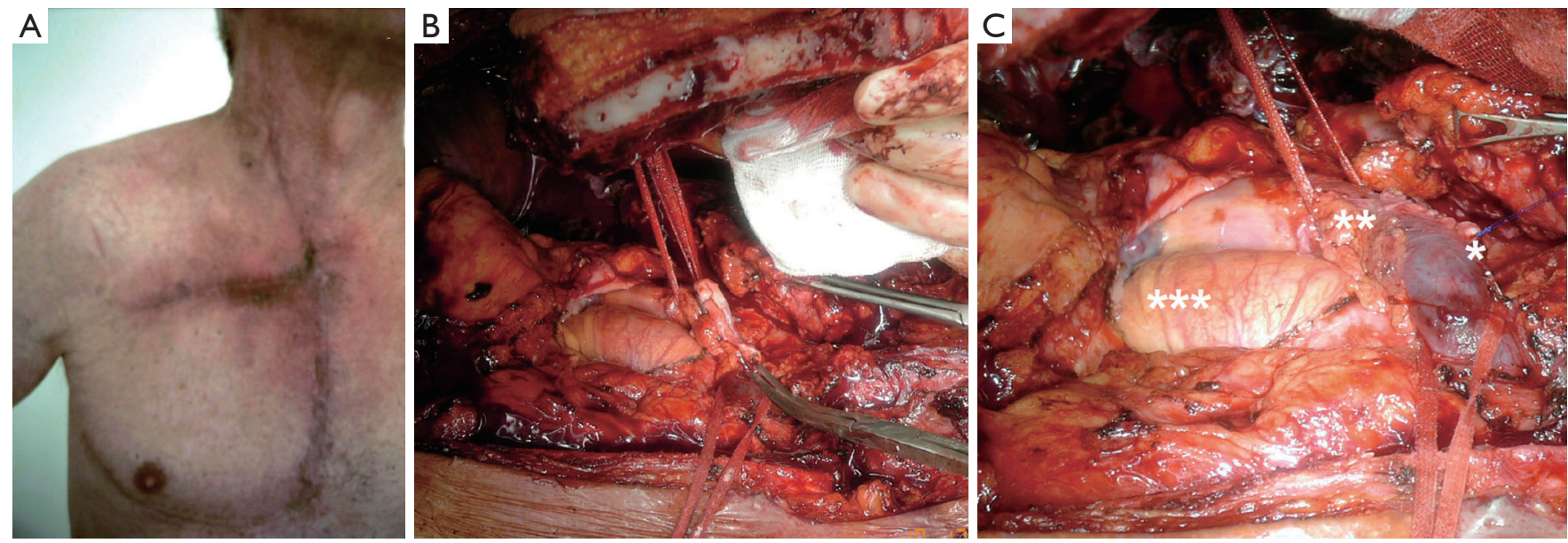

Figure 4 Resection of the involved right brachiocephalic venous trunk. (A) Combined Masaoka and Grunenwald incision for a Pancoast tumor invading the great vessels. (B) and (C) Isolation of the superior vena cava and resection of the right brachiocephalic venous trunk (*, Suture of the sectioned Brachiocephalic venous trunk; **, Superior vena cava; ${ }^{* * *}$, Aortic arch).

of manubrium and two centimeters below the clavicle. The manubrium is sectioned medially and laterally into the second rib, sparing the pectoralis major muscle. As an osteomuscular flap the clavicle and ipsilateral half of sternum can be recanted to expose the thoracic inlet, subclavian vessels and brachial plexus. Finally, the halves of the sternum are joined with wire sutures.

The hemi-clamshell or trapdoor incision could be performed for anterior Pancoast tumors involving the brachiocephalic veins or the jugulo-subclavianbrachiocephalic venous joint (Figure 4) (41). The patient is in the supine position with ipsilateral side elevated. A partial sternotomy with an anterior thoracotomy is performed, and additional resection of the median portion of clavicle for local extension of the tumor can be done to expose the thoracic inlet.

Masaoka (42) described an analogous anterior approach characterized by proximal median sternotomy with anterior thoracotomy in the anterior forth intercostal space and a transverse cervical incision at the base of the neck.

The advantages of this approach are the exposure of the apex of the lung, visualization of subclavian vessels and brachial plexus, safety treatment and easy manipulation of pulmonary hilum during lung resection without changing patient's position. However, in the postoperative period the fail chest can cause respiratory failure.

These procedures to both anterior and posterior Pancoast tumor do not preclude complementary thoracotomic or thoracoscopic approach, if further resections of chest wall of lung are necessary. Namely, as verified by Caronia in 2010 (21) and 2014 (43) VATS technique can offer two major advantages: an intraoperative evaluation of tumor's resectability with a minimally invasive approach and a safe lung resection and nodes dissection without any other extended access. It seems that a combined VATS and open approaches may allow a better outcome than the only open one (43) preserving a high radical resection rate (24).

As underlined by Marulli et al. (23) one of the main challenges remains the management of $\mathrm{T} 4$ disease, mostly in case of vertebral bodies involvement.

Several authors described innovative surgical techniques to resect superior sulcus lung cancers with vertebral invasion. Two different strategies can be considered: complete en bloc resection and intralesional resection.

Gandhi et al. (44) where among the firsts who described intralesional resection. They performed a posterolateral incision through the fifth intercostal space for en bloc resection of the involved ribs and lung parenchyma; thereafter the thoracotomy incision is extended by neurosurgeon as needed to resect the involved vertebrae (Figure 5). A high-speed diamond-tipped electric drill was used to gradually drill out the invaded soft and osseous tissues. If a multilevel laminectomy was performed because of a significant infiltration of the central structures, involved nerve roots were resected too. The capacity to obtain negative margins was associated with a better local control and prognosis.

A similar strategy was applied by Bolton et al. (45). 

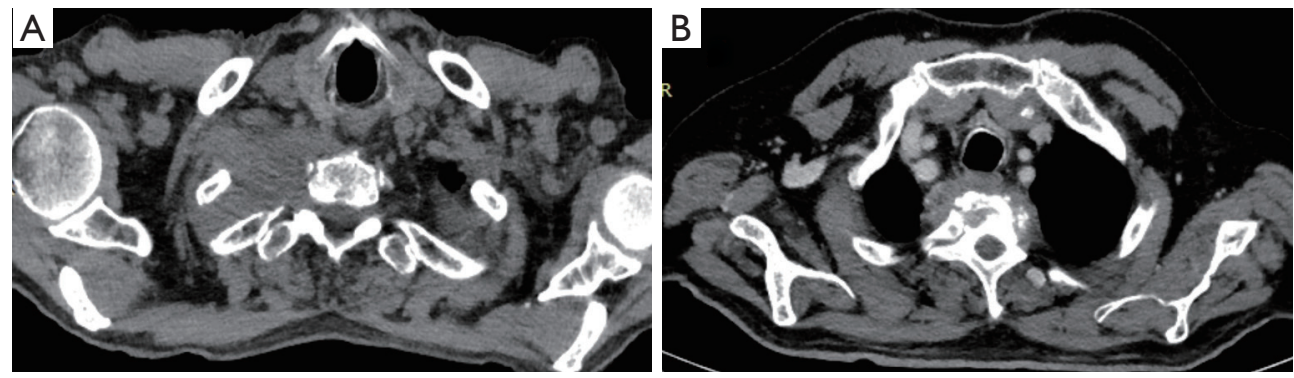

Figure 5 Pancoast tumor invading the spine: (A) the invasion is limited to the transverse process; (B) the tumor infiltrates the vertebral body.

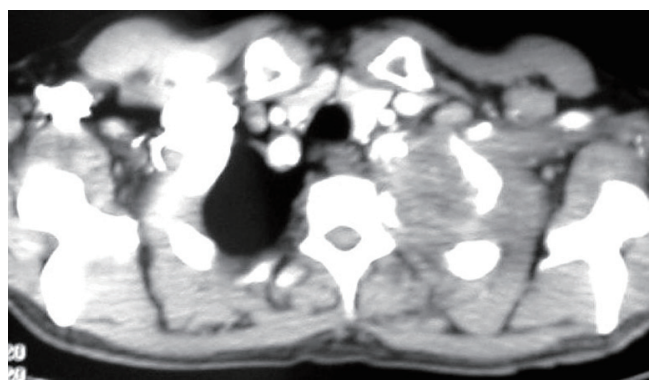

Figure 6 CT scan image of Pancoast tumor invading the anterior and posterior thoracic inlet. In this case, a combined anterior and posterior approaches could be used.

In their study at the beginning, a posterior and rostral extension of the thoracotomy was performed to section the vertebra in the same operation time of the lung resection. At a later time, a double procedure was realized: multilevel laminectomy in prone position in the first operation time and after 24/48 hours a second surgery with thoracotomy and vertebrectomy.

In both studies, the authors realized that the patients who underwent intralesional resection had less morbidity in the immediate post-operative period but a high local recurrence rate. This data can be related to the high rate of not complete resection margins and, potentially, to a not oncologically correct surgical technique.

In 2011, Fadel et al. (22) presented some cases of thoracic inlet and spine invasion treated by a single stage en bloc resection using a combined technique of posterior midline incision and anterior transcervical approach. Schematically, they performed at first the anterior approach followed by the posterior approach for more extended spinal invasion (Figure 6).
Although post-operative morbidity remained high, en bloc resection provided good long-terms outcomes. Data showed $91 \%$ rate of complete resection (R0) and only $13 \%$ of local recurrence. Comparing Bolton and Fadel series, in terms of R0 resection rate, Fadel study obtained a higher result than Bolton series (76\% vs. 56\%). A curative treatment program for NSCLC invading both the thoracic inlet and the spine based on a multimodality approach should therefore largely include en bloc surgical resection of the tumor as a procedure of primary importance.

In the past, vascular infiltration was considered as contraindication to resection, nowadays the anterior approaches have made possible radical resection and reconstruction of invaded vessels. If the tumor infiltrates the subclavian vein it may be resected with ligation with or without revascularization $(46,47)$. The reconstruction with a 6-8 $\mathrm{mm}$ ringed PTFE (Figure 7) is emphasized by some authors (48) in order to minimize the risk of thrombosis and ipsilateral oedema.

In case of adventitial subclavian artery involvement, according to Dartevelle et al. (47) and Alifano et al. (36) a sub adventitial dissection may be accomplished allowing a radical exeresis and avoiding the resection and reconstruction of a great vessel (Figure 8). If the deeper layers are interested, providing an adequate systemic heparinization (e.g., $0.5 \mathrm{mg} / \mathrm{kg}$ ), the subclavian artery can be closed by a clamp upstream the invasion and resected, subsequently revascularized by interposing a polytetrafluoroethylene (PTFE) graft (No 6 or $8 \mathrm{~mm}$ ) or an end-to-end anastomosis (47) (Video 1). The PTFE graft for his tendency to remain patent despite post-operative radiotherapy fibrotic changes is considered the gold standard with low risk of occlusion (39). 

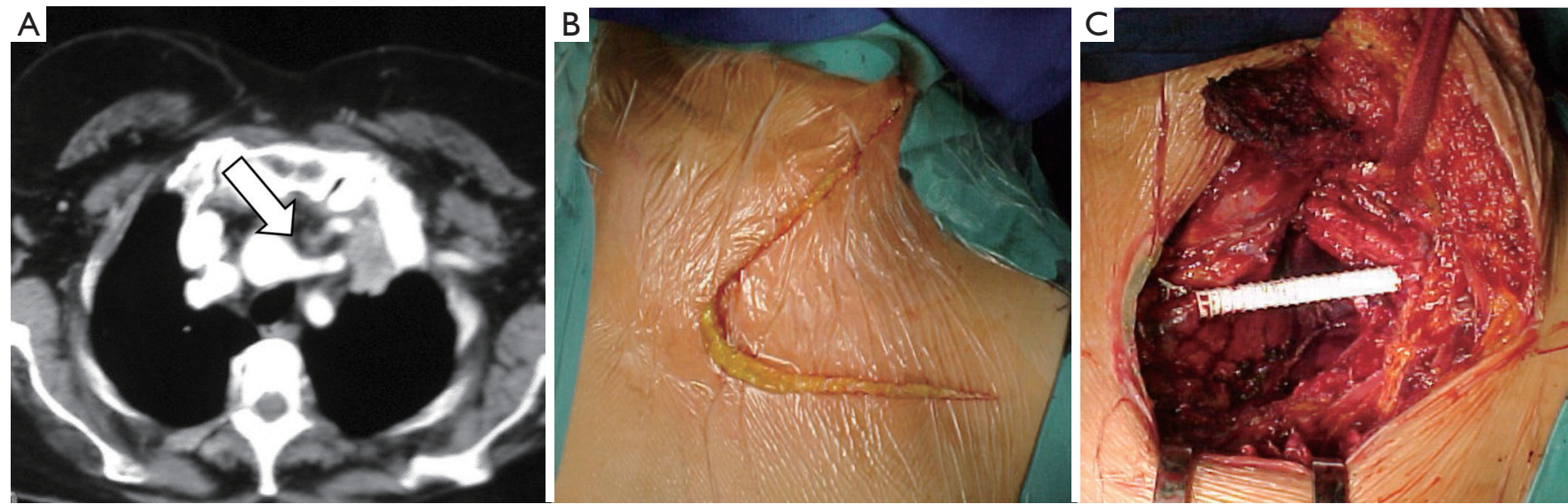

Figure 7 Patient with anterior Pancoast tumor with the subclavian vein involvement. (A) CT scan image showing the vein involvement (white arrow); (B) Grunenwald's skin incision (Transmanubrial L-shaped approach); (C) intraoperative view of revascularization by interposing an armed polytetrafluoroethylene (PTFE) graft of subclavian vein.

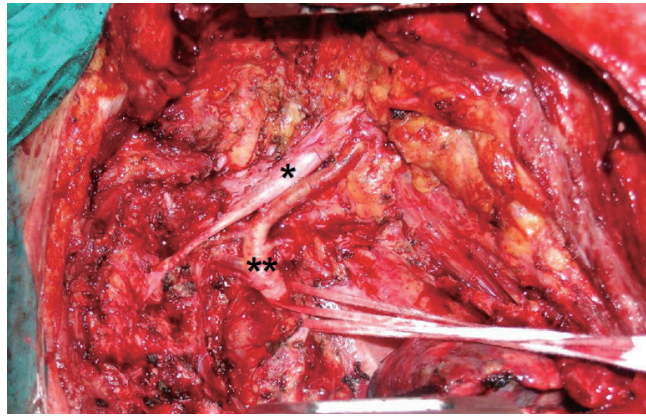

Figure 8 Intraoperative view of isolation and sub-adventitial dissection of the subclavian artery $\left({ }^{*}\right.$, brachial plexus; ${ }^{* *}$, subclavian artery).

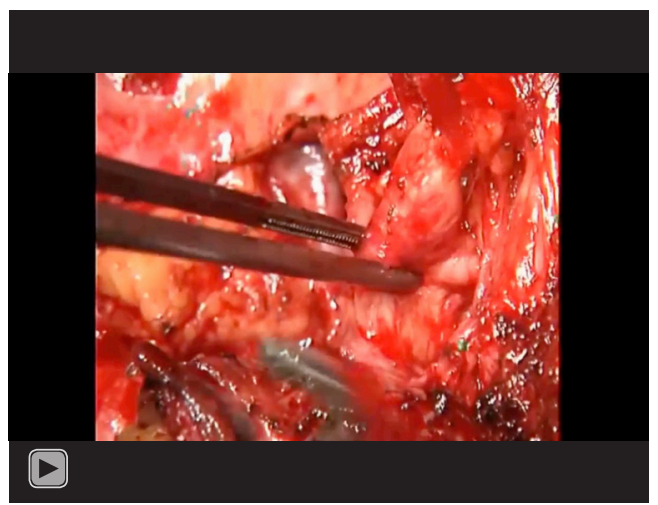

Video 1 Left subclavian artery resection and reconstruction with PTFE graft through a posterior thoracotomic approach.

\section{Acknowledgments}

Funding: None.

\section{Footnote}

Provenance and Peer Review: This article was commissioned by the Guest Editors (Davide Tosi and Alessandro Palleschi) for the series "The treatment of locally advanced lung cancer" published in Current Challenges in Thoracic Surgery. The article has undergone external peer review.

Conflicts of Interest: All authors have completed the ICMJE uniform disclosure form (available at https://ccts. amegroups.com/article/view/10.21037/ccts-20-81/coif). The series "The treatment of locally advanced lung cancer" was commissioned by the editorial office without any funding or sponsorship. GM serves as an unpaid editorial board member of Current Challenges in Thoracic Surgery from January 2020 to December 2021. The authors have no other conflicts of interest to declare.

Ethical Statement: The authors are accountable for all aspects of this work in ensuring that questions related to the accuracy or integrity of any part of this work are appropriately investigated and resolved.

Open Access Statement: This is an Open Access article distributed in accordance with the Creative Commons 
Attribution-NonCommercial-NoDerivs 4.0 International License (CC BY-NC-ND 4.0), which permits the noncommercial replication and distribution of the article with the strict proviso that no changes or edits are made and the original work is properly cited (including links to both the formal publication through the relevant DOI and the license). See: https://creativecommons.org/licenses/by-nc-nd/4.0/.

\section{References}

1. Ginsberg RJ, Martini N, Zaman M, et al. Influence of surgical resection and brachytherapy in the management of superior sulcus tumor. Ann Thorac Surg 1994;57:1440-5.

2. Arcasoy SM, Jett JR. Superior pulmonary sulcus tumors and Pancoast's syndrome. N Engl J Med 1997;337:1370-6.

3. Foroulis C, Zarogoulidis P, Darwiche K, et al. Superior sulcus (Pancoast) tumors: current evidence on diagnosis and radical treatment. J Thorac Dis 2013;5:S342-58.

4. Pancoast HK. Importance of careful roentgen ray investigations of apical chest tumors. JAMA 1924;83:1407-11.

5. Pancoast HK. Superior pulmonary sulcus tumor. Tumor characterized by pain, Horner's syndrome, destruction of bone and atrophy of hand muscles. JAMA 1932;99:1391-6.

6. Tobías JW. Sindrome ápico-costo-vertebral doloroso por tumor apexiano: su valor diagnostico en el cáncer primitivo pulmonar. Rev Med Latino Am 1932;17:1522-56.

7. Walker JE. Superior sulcus pulmonary tumor (Pancoast syndrome). J Med Assoc Ga 1946;35:364.

8. Herbut PA, Watson JS. Tumor of the thoracic inlet producing the Pancoast syndrome; a report of 17 cases and a review of the literature. Arch Pathol (Chic) 1946;42:88-103.

9. Chardack WM, MacCallum JD. Pancoast tumor: five-year survival without recurrence or metastases following radical resection and postoperative irradiation. J Thorac Surg 1956;31:535-42.

10. Paulson DL. The survival rate in superior sulcus tumors treated by presurgical irradiation. JAMA 1966;196:342.

11. Okubo K, Wada H, Fukuse T, et al. Treatment of Pancoast tumors: combined irradiation and radical resection. Thorac Cardiovasc Surg 1995;43:284-6.

12. Kwong KF, Edelman MJ, Suntharalingam M, et al. Highdose radiotherapy in trimodality treatment of Pancoast tumors results in high pathologic complete response rates and excellent long-term survival. J Thorac Cardiovasc Surg 2005;129:1250-7.

13. Albain KS, Rusch VW, Crowley JJ, et al. Concurrent cisplatin/etoposide plus chest radiotherapy followed by surgery for stages IIIA (N2) and IIIB non-small-cell lung cancer: mature results of Southwest Oncology Group phase II study 8805. J Clin Oncol 1995;13:1880-92.

14. Fischer S, Darling G, Pierre AF, et al. Induction chemoradiation therapy followed by surgical resection for non-small cell lung cancer (NSCLC) invading the thoracic inlet. Eur J Cardiothorac Surg 2008;33:1129-34.

15. Marra A, Eberhardt W, Pöttgen C, et al. Induction chemotherapy, concurrent chemoradiation and surgery for Pancoast tumour. Eur Respir J 2007;29:117-26.

16. Shen R, Meyers B, Larner J, et al. Special Treatment Issues in Lung Cancer, ACCP Evidence-Based Clinical Practice Guidelines (2nd Edition). Chest 2007;132:290S-305S.

17. Ettinger DS, Akerley W, Borghaei H, et al. Non-small cell lung cancer, version 2.2013. J Natl Compr Canc Netw 2013;11:645-53.

18. Rusch VW, Giroux DJ, Kraut MJ, et al. Induction Chemoradiation and Surgical Resection for Superior Sulcus Non-Small-Cell Lung Carcinomas: LongTerm Results of Southwest Oncology Group Trial 9416 (Intergroup Trial 0160). J Clin Oncol 2007;25:313-8.

19. Kunitoh H, Kato H, Tsuboi M, et al. Phase II Trial of Preoperative Chemoradiotherapy Followed by Surgical Resection in Patients With Superior Sulcus Non-SmallCell Lung Cancers: Report of Japan Clinical Oncology Group Trial 9806. J Clin Oncol 2008;26:644-9.

20. Rusch VW, Parekh KR, Leon L, et al. Factors determining outcome after surgical resection of T3 and T4 lung cancers of the superior sulcus. J Thorac Cardiovasc Surg 2000;119:1147-53.

21. Caronia FP, Ruffini E, Lo Monte AI. The use of videoassisted thoracic surgery in the management of Pancoast tumors, Interact Cardiovasc Thorac Surg 2010;11:721-6.

22. Fadel E, Missenard G, Court C, et al. Long-Term Outcomes of En Bloc Resection of Non-Small Cell Lung Cancer Invading the Thoracic Inlet and Spine, Ann Thorac Surg 2011;92:1024-30.

23. Marulli G, Battistella L, Perissinotto E, et al. Results of surgical resection after induction chemoradiation for Pancoast tumours. Interact Cardiovasc Thorac Surg 2015;20:805-11.

24. Jiao J, Huang H, Tian L, et al. Anterior or Posterior Approach with Video-assisted Thoracoscopic Surgery for Superior Sulcus Tumors. Zhongguo Fei Ai Za Zhi 2015;18:696-700.

25. Waseda R, Klikovits T, Hoda MA, et al. Trimodality therapy for Pancoast tumors: T4 is not a contraindication 
to radical surgery. J Surg Oncol 2017;116:227-35.

26. Solli P, Casiraghi M, Brambilla D, et al. Surgical Treatment of Superior Sulcus Tumors. A 15-Year SingleCentre Experience. Semin Thorac Cardiovasc Surg 2017;29:79-88.

27. Wright CD, Menard MT, Wain JC, et al. Induction chemoradiation compared with induction radiation for lung cancer involving the superior sulcus. Ann Thorac Surg 2002;73:1541-4.

28. Pourel N, Santelmo N, Naafa N, et al. Concurrent cisplatin/etoposide plus 3D-conformal radiotherapy followed by surgery for stage IIB (superior sulcus T3N0)/ III non-small cell lung cancer yields a high rate of pathological complete response. Eur J Cardiothorac Surg 2008;33:829-36.

29. Kappers I, van Sandick JW, Burgers JA, et al. Results of combined modality treatment in patients with non-smallcell lung cancer of the superior sulcus and the rationale for surgical resection. Eur J Cardiothorac Surg 2009;36:741-6.

30. Favaretto A, Pasello G, Loreggian L, et al. Preoperative concomitant chemo-radiotherapy in superior sulcus tumour: A mono-institutional experience. Lung Cancer 2010;68:228-33.

31. Li J, Dai CH, Shi SB, et al. Induction concurrent chemoradiotherapy compared with induction radiotherapy for superior sulcus non-small cell lung cancer: a retrospective study. Asia Pac J Clin Oncol 2010;6:57-65.

32. Shimada Y, Kudo Y, Maehara S, et al. Significant prognostic determinants in lung cancers of the superior sulcus: comparable analysis of resected and unresected cases. Gen Thorac Cardiovasc Surg 2020;68:801-11.

33. Fridriksson BM, Jónsson S, Oskarsdottir GN, et al. Outcome of surgical treatment for Pancoast lung carcinoma in Iceland[REMOVED HYPERLINK FIELD]. Laeknabladid 2015;101:351-5.

34. Jeannin G, Merle P, Janicot H, et al. Combined treatment modalities in Pancoast tumor: results of a monocentric retrospective study. Chin Clin Oncol 2015;4:39.

35. Nun AB, Simansky D, Rokah M, et al. Hybrid videoassisted and limited open (VALO) resection of superior sulcus tumors. Surg Today 2016;46:686-90.

doi: $10.21037 /$ ccts-20-81

Cite this article as: Signore F, Panza T, Brascia D, De Iaco G, Fiorella A, Schiavone M, Geronimo A, Sampietro D, Rea F, Marulli G. Posterior and anterior sulcus tumors. Curr Chall Thorac Surg 2021;3:5.
36. Alifano M, D'Aiuto M, Magdeleinat P, et al. Surgical Treatment of Superior Sulcus Tumors, Results and Prognostic Factors. Chest 2003;124:996-1003.

37. Rea FA, Marulli G, Sartori F. Postero-Lateral (ShawPaulson) Approach to Pancoast tumor, 2011. Available online: https: //www.ctsnet.org

38. Shaw RR, Paulson DL, Kee JL. Treatment of Superior Sulcus Tumor by Irradiation Followed by Resection. Ann Surg 1961;154:29-40.

39. Dartevelle PG, Chapelier AR, Macchiarini P, et al. Anterior transcervical-thoracic approach for radical resection of lung tumors invading the thoracic inlet. J Thorac Cardiovasc Surg 1993;105:1025-34.

40. Grunenwald D, Spaggiari L. Transmanubrial osteomuscular sparing approach for apical chest tumors. Ann Thorac Surg 1997;63:563-6.

41. Bains MS, Ginsberg RJ, Jones WG, et al. The clamshell incision: an improved approach to bilateral pulmonary and mediastinal tumors. Ann Thorac Surg 1994;58:32-2; discussion 33 .

42. Masaoka A, Ito Y, Yasumitsu T. Anterior approach for tumors of the superior sulcus. J Thorac Cardiovasc Surg 1979;78:413-5.

43. Caronia FP, Fiorelli A, Ruffini E, et al. A comparative analysis of Pancoast tumour resection performed via videoassisted thoracic surgery versus standard open approaches. Interact Cardiovasc Thorac Surg 2014;19:426-35.

44. Gandhi S, Walsh GL, Komaki R, et al. A Multidisciplinary Surgical Approach to Superior Sulcus Tumors With Vertebral Invasion. Ann Thorac Surg 1999;68:1778-84.

45. Bolton WD, Rice DC, Goodyear A. Superior sulcus tumors with vertebral body involvement: a multimodality approach. J Thorac Cardiovasc Surg 2009;137:1379-87.

46. Rusch VW. Management of Pancoast tumours. Lancet Oncol 2006;7:997-1005.

47. Dartevelle P, Macchiarini P. Surgical management of superior sulcus tumors. Oncologist 1999;4:398-407.

48. Nikolaos P, Vasilios L, Efstratios K, et al. Therapeutic modalities for Pancoast tumors. J Thorac Dis 2014;6:S180-93. 